\title{
Una década de historia chicana: revisión historiográfica y crítica
}

\author{
Richard Griswold del Castillo \\ INSTTTUTO MOR A
}

$\mathrm{E}$ n los últimos treinta años se ha escrito bastante sobre los mexicanos que viven en Estados Unidos. Este nuevo interés en el más grande de los grupos de habla hispana se ha desarrollado, en parte, por la crecien. te importancia demográfica y política de los latinos en Estados Unidos. El movimiento para desentrañar las ráces históricas de este grupo étnico se inició realmente durante las décadas de 1960 y 1970 , periodo activista marcado por confrontaciones políticas con el "gobierno establecido". Una joven generación de mexicanoamericanos creó un nuevo campo de investigación histórica al que llamaron historia chicana. ${ }^{1}$ Los primeros escritores de la

${ }^{1}$ En este trabajo el término "chicano" se em- historia chicana fueron revisionistas en desacuerdo con los estudios histó. ricos sobre los mexicanos de Estados Unidos hechos por académicos angloamericanos. A menudo, sin embargo, buscaban reivindicar un pasado que había sido ignorado u olvidado por los académicos de la corriente principal.

A partir de la década de 1960 ha habido una maduración del talento histórico entre los historiadores chicanos en Estados Unidos. El propósito de este artículo es examinar los más recientes trabajos a fin de actualizar a los

plea para referirse a aquellas personas descendientes de mexicanos que se identifican con objetivos que buscan el mejoramiento del estatus social, económico, político y cultural de los mexicanoamericanos en Estados Unidos. 
académicos mexicanos en este rápidamente creciente campo de estudio. Ciertamente que hay puntos de unión entre los principales acontecimientos en la historiografia mexicana con la historia chicana, entre los que destacan la guerra con México y el Tratado de Guadalupe Hidalgo, la revolución mexicana y su relación con los mexicanos asentados en la zona fronteriza, así como las consecuencias sociales, económicas y políticas de más de 100 años de inmigración mexicana a Estados Unidos. Durante muchos años los investigadores chicanos han tenido conciencia de estos puntos de unión, y con frecuencia han recurrido a las fuentes primarias mexicanas para reunir la información que requerían en sus trabajos. También se ha formado un pequeño pero importante grupo de investigadores mexicanos que han escrito sobre temas históricos relacionados con los mexicanoamericanos. El trabajo de estos últimos no es muy conocido y merece un tratamiento historiográfico separado. ${ }^{2}$

Este trabajo se centra en especial en la historia chicana escrita en Estados Unidos durante el periodo 1980-1990. Fue esta década un periodo de excepcional actividad en la producción de trabajos sobre la historia chicana, especialmente en la producción de monografías con la extensión de un libro.

2 Algunos de los más importantes trabajos de naturaleza histórica escritos por mexicanos sobre la historia chicana son: Carreras de Velasco, Mexicanos, 1974; Santamaría Gómez, Izquterda, 1988; Gómez Arnau, México, 1990; Alanís, "Primera", 1987; López y Rivas, Chicano, 1969, Chicanos, 1971, y Guerra, 1976; Cue Cánovas, Estados Untdos, 1970.
Durante el periodo, los historiadores chicanos exploraron nuevos temas y cuestiones, y fueron más allá de las consideraciones polémicas y teóricas de las primeras épocas. Entre 1980 y 1990 se publicaron más de 40 libros sobre historia chicana. Además, por lo menos una docena de libros sobre historia chicana aparecieron en México traducidos al español. Este material se ha desarrollado tan rápidamente que pocos investigadores se han podido dar el lujo de leer todo lo producido, y menos aún han tenido el tiempo de analizar las principales características de su crecimiento. ${ }^{3}$

Una revisión de los más importantes libros de historia chicana publicados en esta década muestra el desarrollo de va. rios nuevos temas de importancia. Temáticamente he dividido a la literatura en seis áreas que se traslapan conceptualmente: 1) estudios comunitarios; 2) investigaciones regionales; 3 ) historia sociocultural e intelectual; 4) historia chicana; 5) historia política, y 6) relaciones Estados Unidos-Méxicochicanos. Después de revisar esta literatura, presento un análisis de la materia como un todo y hago algunas sugerencias respecto de las direccio-

3 Por razones de tipo práctico, este trabajo se centrará principalmente en monografias históricas y en libros publicados en la década de $\mathbf{1 9 8 0}$. Los primeros trabajos historiográficos de ésta son: Zaragoza, "Ideological", 1987; "Recent", 1988-1989; Gutiérrez, "Third", 1989; Acuña, "Struggles", 1990; Ruiz, "Texture", 1986; Griswold, "New", 1984, "Tejanos", 1985, "Southern", 1988-1990; Hoffman, "Writing", 1986; De León, "Texas", 1990; Chávez, "Rubio's", 1988. Para una visión más completa de la literatura histórica hasta 1974, consúltese Gómez Quiñones, "State", 1980. 


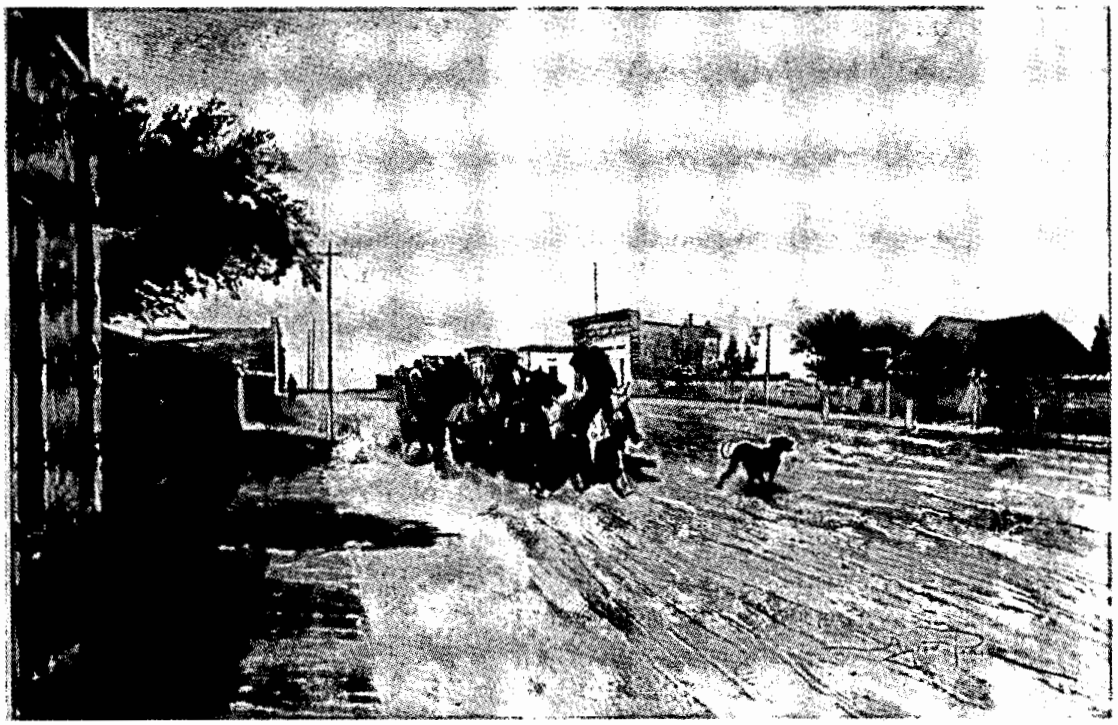

nes futuras que los investigadores podrían tomar.

La década de 1980 fue testigo del abandono de paradigmas marxistas y coloniales internos, y de un movimiento ajeno a la tendencia de centrarse exclusivamente en las formas de opresión económica y social angloamericana con las que se ha victimado a los mexicanos. La mayoria de los historiadores chicanos adoptaron un punto de vista que examinó la complejidad de la comunidad chicana diferenciada por clases, intereses generacionales y de género. La década de 1980 también testimonia el lento pero constante crecimiento de la historia chicana: una preocupación por las formas en que las chicanas y las mexicanas fueron personajes de dramas ignorados por los historiadores activistas masculinos de la década anterior. Finalmente, esta década testimonia la maduración de la materia conforme los historiadores no chicanos comenzaron a interesarse en la investigación y preparación de tra. bajos escritos sobre la historia mexicanoamericana. El resultado fue el desarrollo de una "historia chicanesca": interpretaciones de la historia chicana realizadas por no chicanos. ${ }^{4}$

El clima político y social de la década de 1980 influyó en los trabajos escritos. Los años de Reagan, de retórica conser-

4 El término "chicanesca" es el empleado por los críticos literarios para referirse al tipo de literatura escrita por no chicanos sobre temas chicanos. No tiene necesariamente una connotación peyorativa. 
vadora, de cortes a programas federales y de producción de una "generación del yo", tuvo eco entre los mexicanoamericanos. Los influyentes mexicanoamericanos rechazaron el calificativo "chicano" y adoptaron la ideología y la terminología de la "década del hispano". Las organizaciones nacionales hispanas se enfocaron crecientemente a depender de las donaciones de corporaciones, con lo que se volvieron menos independientes. 5 EI crecimiento de la pobreza entre casi todos los latinos contrastó con el crecimiento de una nueva y próspera clase media latina. No solamente la estructura socioeconómica de clases de los mexicanoamericanos se tornó relativamente más variada, sino que se dio una creciente diversidad en la naturaleza de la propia cultura debido al cambiante carácter de la inmigración de América Latina. En forma creciente, los barrios más viejos, especialmente en el sur de California (que fue la cuna del movimiento estudiantil chicano de la década de los setenta), se convirtieron en lugares para los refugiados de Centroamérica y de Asia.

De esta manera, la historia chicana de esta década se puede resumir en términos de su fragmentación, diversidad y heterogeneidad. La complejidad de la época contemporánea se inserta en el modo en que los historiadores chicanos interpretaron el pasado. Crearon visiones que, aunque no unificadas en el aspecto político, eran más elaboradas que las historias chicanas previas.

5 Véase Ortiz, "Reaganomics", 1989.

\section{ESTUDIO DE COMUNIDADES}

En la primera categoría -estudios comunitarios-, los historiadores chicanos continuaron con una agenda política correspondiente a la época activista anterior: la de contribuir al orgullo comunitario y contar la historia olvidada sobre las contribuciones de los chicanos como parte de la América del pequeño pueblo urbano. En forma particular pretendian reafirmar la vitalidad social y política, así como la creciente importancia demográfica de las comunida. des de habla hispana en Estados Unidos.

Como la más grande población ur. bana de origen mexicano en Estados Unidos, Los Ángeles ha sido la más estudiada. En la década de 1980, los historiadores chicanos produjeron una historia bastante completa del barrio de Los Ángeles en los libros de Griswold del Castillo, Romo, Acuña, Ríos Bustamante y Pedro Castillo, Francisco Balderrama y Mauricio Mazon. Estos trabajos, junto con contribuciones más tempranas de Juan Gómez-Quiñones, Albert Camarillo, Abraham Hoffman y otros, presentan un vívido cuadro histórico del desarrollo de las comunidades mexicanas y chicanas del oriente del río Los Ángeles durante el siglo Xx. ${ }^{6}$ Quedan aún lagunas en

6. Las historias comunitarias escritas en las dos décadas anteriores incluyen: Acuña, Community, 1984; Romo, East, 1983; Griswold, Barrio, 1980; Baiderrama, Defense, 1983; Ríos Bustamante, Illustrated, 1986; Mazon, Zoot, 1984; Muñoz, "Youth", 1989. Los trabajos históricos sobre el barrio de Los Ángeles, publicados antes de 1980, fueron los de Gómez Quiñones, Sembradores, 1973; Camarillo, Chicanos, 1979; Hoffmann, Unwanted, 1974. 
nuestro conocimiento, como la de la comunidad chicana de Los Ángeles durante la época de la gran Depresión y durante la década de 1940 . Irónica. mente, lo que más hace falta es una minuciosa historia del movimiento chicano de las décadas de 1960 y 1970 en Los Ángeles que comprenda tanto las contribuciones de las chicanas como las de los chicanos a las artes, y sus relaciones con otros grupos latinos que llegaron a la ciudad durante esos años.

Los historiadores chicanos de Los Ángeles aún no han sondeado la diversidad del pasado de los habitantes de la ciudad de habla hispana. La mayor parte de la historiografia de los chicanos en Los Ángeles tiende a sobreestimar la homogeneidad de los residentes mexicanos y chicanos. Aunque no en forma abierta, la mayoría de estas historias da como supuesto la existencia, a través del tiempo, de una identificable comunidad de intereses entre los diversos grupos de habla hispana, los de residencia más vieja, los recién llegados, los migrantes urbanos y los campesinos rurales, los hombres y las mujeres, los ricos y los pobres. Ejemplos bien documentados de opresión económica y racial-se presume-forjaron un sentido de comunidad unificada. Este supuesto puede ser erróneo si se considera la también bien documentada transitoriedad y diversidad de la población. A partir de 1990, gran parte de la unidad de la comunidad chicana de Los Ángeles existe como una idea en la mente de los líderes e intelectuales de la comunidad.

En la década de 1980, los historiadores texanos llevaron también a cabo una investigación de las raíces históricas de la comunidad. En Texas la historia comunitaria es dominada por Arnoldo de León, quien fue prácticamente un hombre-industria durante la década de 1980 al producir cuatro libros sobre la historia de los pueblos y ciudades pequeñas: Duval, Benavides, San Ángelo y Houston. En colaboración con Kenneth Stewart también escribió un tra. bajo sobre las comunidades texanas del sur de Texas durante el periodo anterior a 1900.7

A través de su trabajo, De León ha contribuido sustancialmente a documentar la diversidad de la vida y la cultura entre los chicanos de Texas. Su trabajo debe desengañar a aquellos que piensan que existe una comunidad texana unificada. Al hablar de su estudio de. mográfico de los texanos en el siglo XIX dijo: "La comunidad era fundamentalmente diversa en el nacimiento, las ocupaciones, la vida familiar, la educación, los niveles de alfabetización y la residencia urbana/rural. ${ }^{\text {p }}$. Estas diferencias lo han llevado a formular algunas hipótesis sobre las variaciones históricas en la cultura texana que pueden clasificarse desde el punto de vista de las regiones geográficas de Texas.

Esta diversidad de experiencias ha sido subrayada por los trabajos de otros autores texanos en la década de

7 Sin duda, De León ha sido el más prolífico escritor chicano de la década de 1980. Los trabajos que enlistamos no son el total de su producción de este periodo, ya que el resto queda fuera de la categoría de historia comunitaria. Véanse Benavides, 1980, Soctal, 1978, Fiestas, 1978 y Ethnicity, 1989. Su investigación sobre la histo-. ria de la comunidad texana aparece en dos obras: Communtty, 1982 y Tejanos, 1989.

8 De León, "Texas". 
1980. Abel Rubio escribió un libro semibiográfico al estudiar los problemas territoriales comunitarios en el condado Refugio durante el siglo XIX. Gilberto Miguel Hinojosa escribió un libro sobre la historia de Laredo hasta 1870, y Mario García escribió un largo estudio sobre los barrios de El Paso entre 1880 y $1920 .{ }^{\circ}$ En estos trabajos no hubo un consenso respecto de la naturaleza de la comunidad texana. Para Rubel, la tierra y la expoliación mantenían unida a la población; para Hinojosa, las tradiciones coloniales de la familia tenían un papel significativo, y para García la clave recaía en la influencia de la inmigración mexicana. Como el trabajo de De León, estas otras historias de las comunidades se dedicaron a detalles etnográficos respecto de la vida cotidiana y de la familia. En estos trabajos la in. fluencia del racismo angloamericano no recibió un tratamiento de importancia como el que se dio a las tendencias culturales de la sociedad texana. Tanto Hinojosa como García hicieron un esfuerzo especial por delinear las diferencias de las clases socioeconómicas en las comunidades texanas. $\mathrm{El}$ trabajo de Rubio ignoró este factor y continuó con el tema de la lucha del pueblo texano contra la opresión, ubicada dentro del contex to de la historia de su familia.

Como reflejo de su importancia demográfica y política contemporánea para los chicanos, los estudios de California y Texas dominaron la historia de las comunidades durante la década de 1980 . Fuera de dichos estudios, so-

9 Stolen, 1986; Hinojosa, Borderlands, 1983; Garcia, Desert, 1980. lamente se registraron algunas monografias sobre barrios fuera de estas dos regiones. Tom Sheridan escribió un libro importante sobre la comunidad mexicana de Tucson hasta 1941 , mientras que la historia regional de Colorado, de Sarah Deutsch, exploró la historia de numerosos pequeños pueblos desde el punto de vista de las mujeres $y$ de sus familias. ${ }^{10}$ El estudio de Sheridan resaltó la diferenciación de las clases en Tucson, mientras que el de Deutsch hizo hincapié en las diferencias entre los sexos en la historia social y económica.

\section{ESTUDIOS REGIONALES}

Una de las principales quejas con mayor frecuencia recogidas por los historiadores chicanos es la falta de interés de las casas editoriales nacionales (ubicadas en su mayoría en Boston y Nueva York, principalmente) por dar a los mexicanoamericanos un lugar significativo dentro de sus libros de texto sobre historia nacional. Fuera de una fotografia ocasional y de una mención a César Chávez en los libros de tex to de las escuelas secundarias, la historia chicana durante la década de 1980 no logró obtener un reconocimiento nacional igual al dado a algunos otros "grupos minoritarios" del país. ¿Por qué sucedió así?

Las cartas de rechazo a la publicación de sus trabajos que los historiadores chicanos reciben de parte de prestigiosas publicaciones académicas,

10 Sheridan, Tucsonenses, 1986; Deutsch, Separate, 1987. 
con frecuencia señalan que a pesar de que la historia chicana es interesante o incluso está bien escrita, carece de importancia a nivel nacional, y recomiendan que el autor debería "intentarlo en una publicación regional ${ }^{n}$. No obstante los esfuerzos de algunos historiadores chicanos como Rudy Acuña y Mario García por resaltar la importancia nacional de la historia mexicanoamericana durante la década de 1980, la materia continuó siendo calificada como de tipo regional.

Desde el ventajoso punto de vista de los editores de libros de texto y de los alumnos de la ivy league, el suroeste americano (en alguna época el norte de México) carece del peso político que tiene la costa este. Como resultado de esta actitud, millones de estudian- tes emplean gran parte de su tiempo en la lectura de historias locales sobre las trece colonias inglesas, que se presume forman la médula esencial de la historia colonial de Estados Unidos. De esta manera, los estudiantes continúan ignorando totalmente la vida social, política e intelectual de las colonias y provincias de habla hispana que más tarde serían parte de ese país.

Uno de los argumentos que se esgrimen para justificar este error es que, hasta años recientes, los mexicanoamericanos carecían de importancia demográfica significativa en Estados Unidos. Sin embargo, este mismo argumento se podría esgrimir respecto de los indios norteamericanos (quienes representan menos de $1 \%$ de la población nacional, comparada con




aproximadamente el $4 \%$ que los mexicanoamericanos representan en el total nacional). No obstante, en los libros de texto de la historia moderna de Estados Unidos se está otorgando una atención cuantitativamente mayor a los nativos norteamericanos que a los mexicanoamericanos. En el caso de los indios y de los africanoamericanos, es de suponer que su historia se incluye (frecuentemente de una manera par. cial y no satisfactoria desde el punto de vista de los académicos africanoamericanos e indios) porque desde sus inicios está vinculada a la de los colonia. listas ingleses. Los angloamericanos no se enfrentaron con la población de habla española sino hasta después de la revolución norteamericana. De ahí que parte de la explicación de la relativa falta de atención nacional a la historia mexicanoamericana sea el etnocentrismo norteamericano. La historia chicana es considerada importante en tanto que está relacionada con el drama de la población angloparlante de Estados Unidos. Lo mismo sucede respecto de la historia de los indios norteamericanos y de los africanoamericanos, salvo que su interacción ha sido más constante. ${ }^{11}$

11 Todos los libros de texto de historia de Estados Unidos comprenden una sección que trata de la Guerra Mexicana, y es en esta sección donde los estudiantes, por primera vez, toman conocimiento de los mexicanos que hoy día viven en Estados Unidos. Sin embargo, con posterioridad a 1848 desaparecen, quizá para reaparecer en la década de 1960, marchando en las manifestaciones de los trabajadores agrícolas. Una desaparición similar experimentaron los indios norteamericanos y, en menor grado, los afronorteamericanos. El mejor texto de nivel educativo superior actual, que ha recibido elo-
Todo ello se relaciona con problemas mayores del discurso hegemónico y del colonialismo mundial, tan bien analizado recientemente por Edward Said y, antes que él, por Franz Fannon. ${ }^{12}$ Dadas estas limitaciones, sería imposible la existencia de una narrativa histórica nacional sin deformaciones o estereotipos. Por el momento, un buen inicio sería encargar la elaboración de un libro de texto de historia nacional cuyo coautor fuera un historiador chicano (¿con un afroamericano y un nativo norteamericano?). Pero hay que sentarse a esperar a que esta modesta ocurrencia se materialice.

Durante la década de 1980 los historiadores chicanos escribieron algunas muy buenas historias regionales, y es factible que su calidad demande su inclusión en futuros textos. La más im. portante y mejor recibida por el público nacional fue el trabajo de David Montejano, Anglos and mexicans in the making of Texas, 1836-1986. Este libro ganó varios premios nacionales, incluso el prestigiado premio Frederick Jackson Turner de la Asociación Histórica Americana. Montejano, doctor en sociología, desarrolló un sistema de interpretación mundial de la relación anglo-mexicana, y alegaba que las fuerzas del mercado, más que cualquier otro factor, conformaron las relaciones raciales en Texas. Aunque criticado por algunos autores por concentrarse de-

gios por intentar una inclusión nacional de los mexicanoamericanos, es Nash, American, 1986. Sin embargo, la versión para escuelas secundarias de este texto presenta omisiones de importancia.

12 Said, Orientalism, 1978; Fannon, Wretched, 1963. 


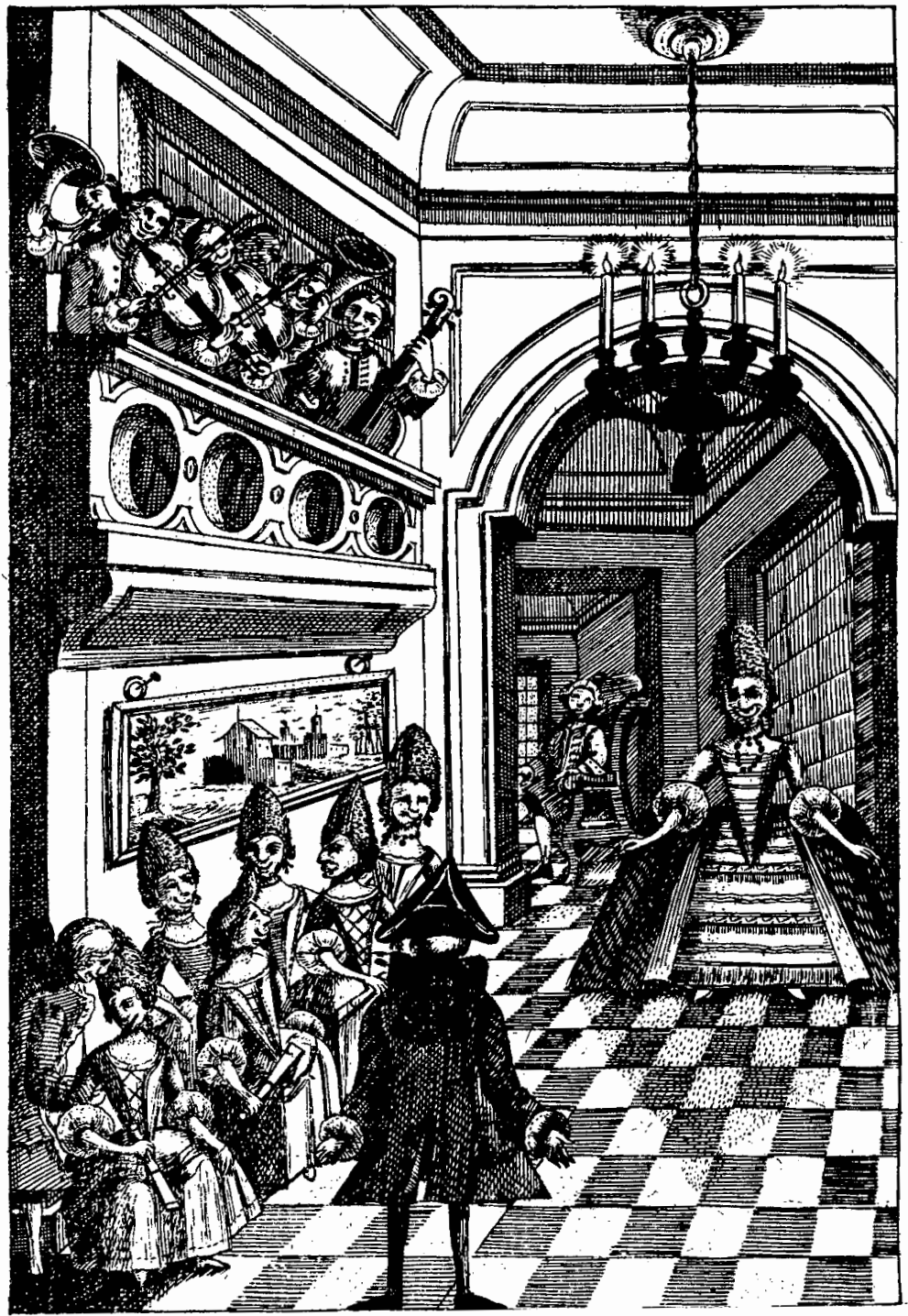


masiado en las elites de origen inglés y muy poco en las acciones de los texanos de carne y hueso que vivieron la historia, el libro logró amplio reconocimiento por sus enfoques metodológicos y teóricos. ${ }^{13}$

Otra historia regional de influencia fue la tercera edición de Occupied America de Rudolfo Acuña, publicado por Prentice Hall. Reorganizado para seguir un formato más cronológico, este texto ha sido un best seller como texto prescrito para la enseñanza de la historia chicana, particularmente en California. Esta edición se distinguió por haber abandonado el argumento colonialista interno que apareció en ediciones anteriores. Fue también de importancia el haber tratado de incorporar un poco más de la historia de los chicanos del oeste medio y del noroeste. ${ }^{14}$ El cambio del subtítulo "La batalla chicana por la liberación" por el de "Una historia de los chicanos" indicó un matizen el énfasis, tendenciageneralizada durante la década de 1980 . No obstante, el texto conservó su tono crítico e incluso combativo que había caracterizado a las ediciones anteriores.

Otros tres trabajos publicados durante la década de 1980 se convirtieron en importantes textos suplemen. tarios en los centros de enseñanza a nivel preparatoria. El libro de Alberto Camarillo Chicanos in California fue un resumen de la historia chicana en el

13 Montejano, Anglos, 1987. Véanse las resenas de Mario García en Hispanic American Historical Revtew, vol. 94, núm. 3, junio 1989, pp. 1184-1185, y de Tomás Chávez en The Journal of American History, vol. 73, núm. 3, diciembre 1988 , pp. 993.994.

14 Ácuña, Occrupied, 1987. estado desde, 1769 hasta el presente; el libro es relatado por un trabajador, y en él se hace un esfuerzo especial por incluir la historia de chicanas destacadas. En su obra Mexicano resistance in the Southwest, Robert Rosenbaum presentó una historia de los movimientos de la resistencia mexicana en el suroeste durante el siglo XIX, con especial atención a Nuevo México. Irónicamente, este libro desarrolló temas de confrontación que durante esa década estaban recibiendo menor atención por parte de numerosos historiadores chicanos. Sin embargo, su argumento - el que los chicanos fracasaban en sus movimientos de resistencia principalmente porque carecían de un sentido de identificación nacional-consistía en una revisión de los conceptos respecto de la naturaleza de la lucha chicana. ${ }^{15}$

Otros estudios regionales de la época fueron reinterpretaciones significativas de la historia colonial española de Arizona y de California. Dos trabajos de importancia, basados en un trabajo sustancial en archivos, fueron Hispanic Arizona de James Officer y Thrown among strangers de Douglas Monroy. El libro de Officer sobre la historia de Arizona durante los periodos españoly mexicano, ofrece una crónica que puede calificarse de vulgar, aunque académica, de la relación entre la historia tem. prana de Arizona y la política de Sonora. Este fue el primer trabajo profundo acerca de este periodo de la historia de Arizona desde el precursor tra-

15 Rosenbaum, Mexicano, 1981. Esta fue una revisión de análisis hobsbawmianos anteriores como los de Castillo, Furta, 1973. 
bajo de Hubert Howe Bancroft en la década de 1870. El libro de Douglas Monroy, por otro lado, es una gema literaria y un ambicioso intento de de. cir algo nuevo respecto del trillado campo de la historia española y mexicana de California (así como de las primeras décadas del periodo estadunidense). Thrown among stangers es un exitoso trabajo que en tono narrativo presenta una interpretación actualizada de la literatura social científica del momento y un tipo de destrucción de la literatura de archivo raramente observada entre los investigadores más viejos. Monroy buscaba contar la historia de California desde el punto de vista de los indios, de los españoles, de los mexicanos y de los anglos, a la vez que prestaba atención a cuestiones de sexo y diferenciación de clase. Su estilo literario, narrativo, hace de su trabajo, en mi opinión, uno de los libros de historia chicana mejor escritos. ${ }^{16}$

Un estudio regional de influencia publicado en 1982 fue la sintesis The mexican frontier, 1821-1848 de David J. Weber. Escrito en un estilo fresco y con el producto de una cuantiosa y cuidadosa investigación documental, Weber apuntó las razones por las cuales México no pudo conservar sus territorios del lejano norte. En su opinión, fueron problemas relacionados con la distancia y la debilidad administrativa del centro (la ciudad de México), así como la voracidad de los co. merciantes norteamericanos y la hostilidad de los indios. Con este libro, los historiadores chicanos recibieron un muy necesitado prólogo en el que

16 Monroy, Thrown, 1990. pudieran basar sus propios estudios regionales. Como tal, es un compañero valioso de The spanish borderlands frontier de John Francis. ${ }^{17}$

El único intento que se hizo por escribir una historia nacional durante este periodo fue el trabajo de dos autores angloamericanos: L. H. Gann y Peter J. Duignan. Estos autores pretendían trazar una historia de todas las personas de habla hispana en Estados Unidos. Hispanics in the United States buscaba unificar la disparidad y diversidad de las historias de los mexicanoamericanos, los puertorriqueños y los cubanos, y contribuir a la discusión de problemas y temas de actualidad. El título del libro demuestra una tendencia política conservadora de los autores, y su argumento -el que todos los "hispánicos" eran básicamente como todos los inmigrantes europeos y que deseaban participar del éxito material norteamericano- aseguró una respuesta crítica de sus lectores chicanos y de los críticos. Se puede considerar que la principal aportación del libro fue el haber espoleado a los historiadores chicanos para comenzar a tomar en cuenta la historia de otros latinos por la relación que tienen con el grupo de descendientes mexicanos.

\section{HISTORIA SOCIOCULTUR AL E INTELECTUAL}

Bajo este rubro considero a los trabajos que han resaltado temas distintos a los regionales y a los comunitarios y que además se centran, principalmen-

17 Weber, Mexican, 1982; Bannon, Spanish, 1970. 




te, en las ideas y la cultura de los mexicanos en Estados Unidos. El desarrollo de un cuerpo de trabajo respetable que pudiera ser llamado historia chicana de las ideas constituía un nuevo desarrollo que patentizaba la maduración de la materia de estudio.

Probablemente uno de los mejores trabajos, nominado para el Premio Pulitzer y escrito con talento literario, fue The lost land: The chicano image of the Southwest de John Chávez. En su libro, Chávez examinó la contradicción y ambivalencia de sentimientos de los chicanos respecto de la región en la cual viven, el suroeste de Estados Unidos (norte de México con anterioridad a 1848). El título del libro se refiere no solamente a la conquista norteamericana, sino también a la enajenación emocional e intelectual que han sufrido (y expresado) los chicanos a través de los años. En They called them greasers, Arnoldo de León también exploró la idea de la enajenación, pero desde un punto de vista angloamericano. Su examen se centró en el sentimiento racista entre los anglotexanos durante el siglo XIX, y detalla sin adornos las formas que utilizaron para construir un "texano distinto".

La elevada calidad general de las investigaciones y trabajos académicos en el campo de la historia intelectual continuaron con la publicación del desafiante trabajo de Mauricio Mazon sobre los disturbios zoot suit en Los Ángeles. Zoot suit riots: The psychology of symbolic annihilation fue un estudio psicosocial complejo que presen- 
tó una interpretación radicalmente nueva de un suceso muy conocido. La tesis de Mazon sostenía que los llamados "disturbios" fueron el resultado de una ruptura en la disciplina militar aunada a las necesidades demostrativas de la sociedad angloamericana de un chivo expiatorio. ${ }^{18}$ Formado por su experiencia como clínico, la psicohistoria de Mazon introdujo una perspectiva que dio una nueva dimensión a un suceso engañosamente simple.

La fertilización cruzada de las perspectivas disciplinarias en esta década hizo mucho hincapié en la historia chicana. Durante la década, varias personas ajenas a la historia, principalmente sociólogos, escribieron importantes trabajos históricos. En este grupo se insertan Montejano así como las historias escritas por Mario Barrera, Robert Álvarez, Alfredo Mirande y algunas otras más que se analizarán en secciones posteriores. En el área de la historia cultural e intelectual Manuel Peña y Guadalupe San Miguel, sin ser historiadores, dieron nuevas perspectivas en este campo. Peña, antropólogo y músico, en The Texas-mexican conjunto: History of a working class music, estudió las implicaciones sociales y económicas de la expresión musical en una sociedad mexicanoa. mericana crecientemente diferenciada. Peña vincula expresamente el nacimiento de la forma de conjunto musical como clase con una forma específica de resistencia a la norteamericanización, y un rechazo de las formas musicales más aculturadas adoptadas por la clase media mexicanoamericana. Guadalu-

18 Mazon, Zoot, 1984. pe San Miguel, educador, restó importancia a las divisiones de clase en el seno de la comunidad texana en Let them all take heed al hacer una crónica de las formas en las cuales los texanos lucharon contra la discriminación en Texas y adoptaron nuevas ideas y estrategias diferentes de las directrices asimilacionistas de los años previos a la segunda guerra mundial. San Miguel subrayó el activo papel desem. peñado por varias organizaciones texanas al oponerse a la segregación y al proponer ideas que consideraban me. jorarían la educación de sus hijos. ${ }^{19}$

Otro estudio histórico de la lucha educativa, publicado durante la década de 1980, fue Chicano education in the era of segregation de Gilbert González. Este trabajo es un estudio del mecanismo de segregación educativa de jure puesto en práctica por la agencia de escuelas estadunidenses después de la primera guerra mundial en el suroeste y sur de California. La última mitad del libro presenta una crónica de los esfuerzos en contra de la segregación después de la segunda guerra mundial, en particular de aquellos esfuerzos encaminados al trascendental caso de Mendez vs. Westminster School District. El enfoque de González analizaba las razones de tipo económico detrás de la segregación escolar. Observó cómo, tanto las organizaciones chicanas de la clase media como las de la clase trabajadora unidas, desarrollaron estrategias para me.

19 Peña, Texas, 1985; San Miguel, Let, 1987. Ambos libros son comparados y reseñados por Gutiérrez en "Third", 1989, pp. 281-297. 
jorar las oportunidades educativas de sus hijos. ${ }^{20}$

Durante la década de 1980 los historiadores chicanos revisaron los puntos de vista respecto del papel histórico de la clase media mexicanoamericana. Insultados con los motes de tío tacos o vendidos durante la década de 1960 y 1970, en la América posmoderna descubrimos que en realidad éstos fueron los no proclamados precursores de la militante década de 1960 . Esta nueva valoración de un elemento de clase en la comunidad chicana, cuya validez hasta ese momento solamente había sido sospechada, coincide con el crecimiento de esta misma clase entre los mexicanoamericanos. El trabajo de

20 González, Chicano, 1990.
Mario García Mexican americans: Leadership, ideology and identity, 1930-1960 demostró que archivos nunca consultados hasta entonces contenían una biografia colectiva de mexicanoamericanos influyentes, representativos de una "generación mexicanoamericana". Este era un grupo de ciudadanos por nacimiento que adquirieron su mayoría de edad durante las décadas de la Depresión y conserva. ron su influencia hasta el inicio del movimiento chicano en la década de 1960. Aprecio por el patriotismo, democracia electoral, educación formal e integración fueron los objetivos de importantes organizaciones que obtuvieron logros para los derechos civiles de los mexicanoamericanos durante las décadas previas a la de 1960 . Este

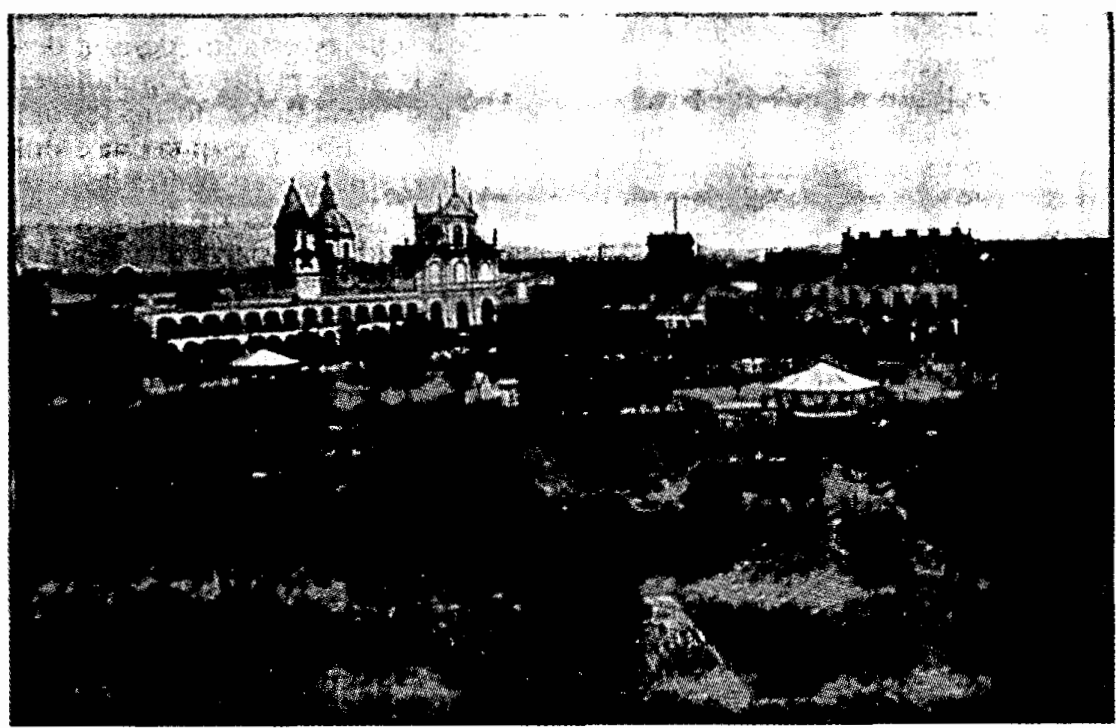


grupo se integró principalmente por hombres de clase media, aunque también formaron parte de él algunas mujeres y algunos miembros de la clase trabajadora.

Otra decisiva contribución a la historia de las ideas, así como del factor de clase en la historia chicana, fue el estudio de Richard García sobre la clase media mexicanoamericana en San Antonio, Texas, durante la década de 1930. Su análisis de la lucha entre las elites mexicanoamericanas nativas y las elites inmigrantes por el control de la cultura local está revestido de un sugestivo interés. Ilustra la fragmenta. ción de la comunidad debida a razones de competencia económica de clase así como de nacionalidad. Como una muy importante contribución a la historia social chicana, el libro de Garcia analiza el desarrollo de lo mexicano cuando se confronta a lo norteamericano. ${ }^{21}$

\section{HISTORIA CHICANA}

En la década de 1980 proliferaron los estudios históricos sobre los sexos como una respuesta a un creciente movimiento chicano que en su inicio demandó la inclusión y, posteriormente, la independencia (ęliberación?) de la historia centrada en los hombres y dominada por ellos. Las mujeres chicanas, principalmente, escribieron su propia historia aunque también aparecieron estudios notables escritos por hombres acerca de la historia de las mujeres.

${ }^{21}$ García, Rise, 1990.
Ramón Gutiérrez y Richard Griswold del Castillo escribieron libros en los que trataron temas de interés para las mujeres chicanas: política sexual, estrategias matrimoniales con una orientación de clase, opresión de los sexos y subversión al patriarcado. ${ }^{22}$ Ambos autores utilizaron técnicas cuantitativas en un esfuerzo por emplear expresiones no literarias sobre las relaciones de sexo; asimismo, explotaron una cantidad considerable de fuentes primarias cuya utilidad se había menospreciado en anteriores trabajos históricos. Los dos trabajos estudiaron las principales cuestiones de los cambios en la familia y las relaciones sexuales entre las chica. nas de origen mexicano, si bien se centraron en diferentes épocas y puntos geográficos.

Estos dos libros, escritos por hombres, no subrayaron la intervención femenina -las mujeres no fueron vistas como los principales actores en la construcción de su propio mundo. La principal directriz dada a la historia chicana escrita por mujeres fue la de "dotar de poder" a las mujeres al interpretar las acciones históricas de éstas como eficaces. Sarah Deutsch, por ejemplo, en el libro No separate refuge, mostró cómo las mujeres del norte de Nuevo México y del sur de Colorado cambiaron la vida de los pueblos durante el periodo 1880-1940. Para ella, las mujeres hispanas desempeñaron un papel central en la mediación de las consecuencias culturales de los cambios económicos. De la misma manera, Vickie Ruiz, en su libro Cannery 22 Gutiérrez, When, 1990; Griswold, Familla, 1984. 
women, cannery lives, cuenta las historias de olvidadas líderes sindicales chicanas durante la década de 1930 y arguye que habían tenido un papel sig. nificativo en la organización de los sin. dicatos. También presenta a los lectores un relato sobre las rutinas del trabajo diario y sobre las luchas de las chicanas en las naves de empaque. En su antología editada con Susan Tiano, Women on the U.S. Mexico border: Responses to change, reunió una colección de trabajos que reflejan cómo las mujeres han tenido un papel históri$\infty$ activo a lo largo de la línea fronteriza internacional. ${ }^{23}$ En Women's work and chicano families, Patricia Zavella utilizó también detallados estudios de caso, como lo hiciera Vikie Ruiz, para investigar sobre las vidas de las trabajadoras mexicanas y chicanas en las empacadoras del valle de Santa Clara (California) en un periodo más reciente, 1977-1978. Zavella encontró que las mujeres cambiaron sus propias vidas como mujeres trabajadoras al establecer en el empleo redes de comunicación con otras mujeres. Estas redes les proporcionaron las bases de una fuerza emocional así como organizativa. Zavella concluyó afirmando que las expec. tativas del papel básico de las mujeres en el seno de la familia no cambiaron significativamente por más que condujeran a numerosos conf lictos. ${ }^{24}$

La historia de las chicanas se encuentra aún en su infancia, como una nueva era dentro de los estudios chicanos. Dos trabajos publicados en la dé-

23 Ruiz y Tiano, Women, 1987.

24 Deutsch, Separate, 1987; Ruiz, Cannery, 1987; Zavella, Women's, 1987. cada de 1980 mostraron las posibilidades de futuras directrices. Julia Kirk Backwelder hizo un estudio comparativo entre mujeres -negras, blancas $\mathrm{y}^{\circ}$ mexicanas-en San Antonio durante la gran Depresión. Este trabajo monográfico exploró las dimensiones sociales, políticas y culturales de la segregación racial en una ciudad de Texas. Mediante el análisis estadístico y el uso de la técnica del estudio de caso, Kirk Blackwelder utilizó una metodología cuantitativa estadística para documentar la primacía de la raza y la casta en las relaciones sociales entre las mujeres y la sociedad más amplia. El marco com. parativo utilizado subrayó la gran autoridad de las conclusiones de la autora. La antología editada de Adelaida del Castillo, Between borders: Essays on mexicana/chicana history es una colección de trabajos, tanto de hombres como de mujeres, sobre una amplia variedad de temas históricos: teoría, metodología, organización del trabajo, inmigración, educación, folklore, patriarcado y feminismo. Una dimensión adicional fue la incorporación de varios temas sobre la historia de las mujeres mexicanas, que interpretó como parte integral del patrimonio de la chicana. Este libro destacó la diversidad y actualidad de la historia de la mexicana y de la chicana. Sirvió también para estimular una mayor erudición en los estudios feministas. ${ }^{25}$

Conforme inicien sus carreras los recientemente doctorados en historia chicana, será factible contar con la próxima publicación de un mayor nú-

25 Blackwelder, Women, 1984; Castillo, Betureen, 1990. 
mero de monografias y trabajos sobre historia chicana. Servirán como modelo para la década de 1990 los estudios históricos de gran calidad publicados durante esta década.

\section{HISTORIA POLITICA}

La historia chicana es, por definición, historia política toda vez que el mero relato de la existencia de una realidad mexicano/chicana en Estados Unidos pone a prueba una visión ortodoxa -aquella que considera tales actividades fuera del canon de la experiencia americana. En esta sección, sin embargo, analizo aquellos trabajos que se han ocupado en forma especial de evaluar las actividades políticas de chicanos y mexicanos en el pasado, o de criticar indirectamente el tratamiento histórico dado a los mexicanos y chicanos por las instituciones angloamericanas. La principal directriz de la historia política chicana, conforme se desarrolló en épocas de mayor militancia, continuó teniendo validez. El fin implícito y explícito de estas historias políticas chicanas fue actuar como una guía para la futura acción política. La autoría del mayor número de estas historias políticas corresponde a científicos políticos y sociólogos, pero no a historiadores. Esto se puede atribuir a un número de factores: la naturaleza multidisciplinaria de los estudios chicanos según se imparten en las universidades; la falta de historiadores capacitados respecto de la amplitud de la tarea y la riqueza de las fuentes primarias cuya importancia trasciende las disciplinas.
En la década de 1980 algunas de las personas que participaron intensamente en la política del movimiento chicano comenzaron a escribir sus propias interpretaciones de este periodo. En sus análisis del pasado inmediato buscaron encontrar una lección para la futura acción política, más que caer en la estéril discusión de la teoría. En general, las historias políticas chicanas trataron de transmitir las lecciones políticas del movimiento chicano a la siguiente generación de activistas.

Juan Gómez-Quiñones, historiador, probablemente ha escrito la hasta ahora más completa y amplia investigación del pasado político reciente. Chicano politics: Reality an promise, 1940-1990, obra concebida como el primero de dos volúmenes sobre la historia política chicana. En ella presenta un sofisticado examen de la naturaleza de la actividad política chicana (llamada mexicana) desde la segunda guerra mundial. Se preocupa por los matices de la clase socioeconómica, la generación, la ideología, el origen nacional, la raza y la identidad al presentar una critica del liberalismo norteamericano (llamado pluralismo liberal) y su percepción de la política mexicana. Para Gómez-Quiñones, la política chicana es "una expresión de una consciente lucha económica y cultural, un conflicto de intereses engendrado por la explotación y los conflictos surgidos de la opresión de grupo que siempre han dominado la vida de los mexicanos". ${ }^{26}$

Otros dos libros escritos por activos participantes en el movimiento chicano tuvieron objetivos menos amplios;

26 Gómez-Quiñones, Chicano, 1990, p. 28. 
sin embargo, están escritos en tonos prescriptivos y críticos; éste es el caso de Youth, identily, power: The chicano movement de Carlos Muñoz, Jr., y de United we win: The rise and fall of La Raza Unida Party de Ignacio M. García. ${ }^{27}$ A mbos libros tuvieron los aciertos y errores de las historias que relataban, son ricos en detalle y refieren los hechos con voz fuerte; sus interpretaciones de la historia reciente reflejan sus propios papeles en la formación de la historia.

Carlos Muñoz, quien tuvo una activa participación en el movimiento estudiantil chicano y en el Partido de la Raza Unida, estaba convencido de que los historiadores habian ignorado el grado en el cual el activismo de las dé. cadas de 1960 y 1970 se debió al poder y a la vitalidad de las generaciones más jóvenes. Escribió su análisis de los sucesos y de los líderes clave del movimiento estudiantil chicano, no sin an. tes examinar el contexto histórico de la organización política durante el periodo 1930-1960. Para Muñoz, el tema principal fue el de la identidad. Pertenecer a un grupo étnico, ser trabaja. dor, sentir una inclinación por los me. xicanos o ser "americanizado" son cuestiones que han estado dentro de las numerosas luchas de las organiza. ciones estudiantiles. Para Muñoz, el movimiento estudiantil chicano fue el primero en la historia política chicana en el que los mexicanos en Estados Unidos pretendían basar su organización en una identificación étnica y de clase trabajadora. La contribución original de Muñoz fue la documentación

27 Muñoz, Youth, 1989; García, United, 1989. y evaluación de las tácticas y estrategias del liderazgo estudiantil, y llevó su análisis al entonces presente 1989.

Ignacio M. García, miembro organizador del Partido de la Raza Unida durante la década de 1970 , conoció personalmente a muchos de los líderes chicanos, quienes son los principales actores de su libro. Como Muñoz, tuvo acceso a los papeles y registros que una persona ajena nunca hubiera podido consultar. También como Muñoz, García tenía interés en analizar detalladamente los éxitos y, en última instancia, los fracasos del Partido de la Raza Unida, de manera que los futuros organizadores "aprendieran de la historia". El resultado fue una apreciación honesta del problema creado por el éxito del Partido de la Raza Unida. Temerosos de los beneficios que pudieran derivarse para el Partido de la Raza Uni$\mathrm{da}$, las agencias federales y estatales comenzaron una campaña de sistemá. tica vigilancia y hostigamiento. Los éxitos electorales del Partido de la Raza Unida contribuyeron a la apertura del sistema de manera que los mexicanoamericanos pudieran ganar elecciones como candidatos de partidos importantes. Su programa político fracasó y el Partido de la Raza Unida finalmente expiró como partido político.

Aparecieron otras historias institucionales u organizativas. Una de éstas, escrita por Carl Allsup, pretendía natrar la historia de la fundación y el de. sarrollo de una organización chicana de veteranos, el American G. I. Forum. ${ }^{28}$ El libro de Allup es más un himno acrítico dedicado al liderazgo del

28 Allsup, American, 1982. 


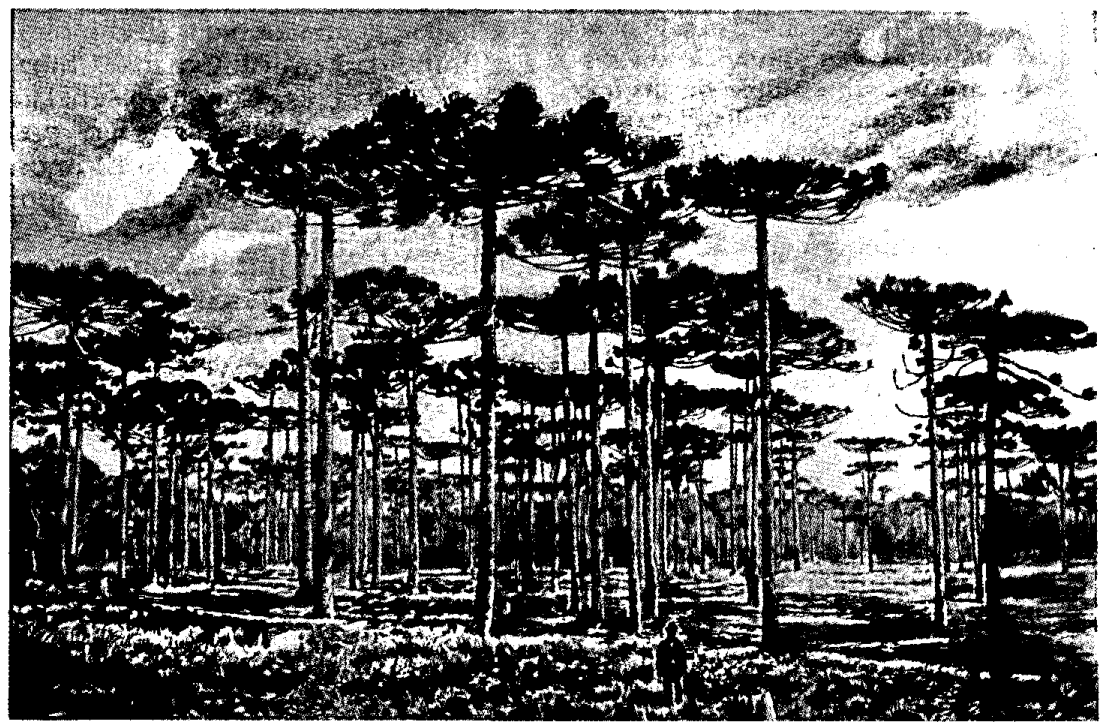

Forum que un estudio crítico de la controvertida postura política de esta organización sobre asuntos polémicos; sin embargo, el libro fue un valioso primer paso para la crónica del crecimiento de dicha organización.

Julián Samora y Alfredo Mirande son autores de una crítica más mordaz de las instituciones políticas en sus dos historias políticas. ${ }^{29}$ Samora y sus colaboradores presentaron una muy necesitada revisión crítica de las historias de los Texas rangers. Los autores utilizaron fuentes primarias, incluso entrevistas y periódicos, para documentar históricamente evidencias que indicaban el abuso de autoridad por parte de

29 Mirande, Gringo, 1987; Samora y otros, Gunpowder, 1979. los rangers en su relación con los mexicanos y los chicanos. Los autores concluyeron su investigación señalando que los rangers tuvieron un efecto negativo sobre el sistema de Texas de aplicación de la ley. Los autores recomendaron la abolición de los rangers ya que "habían tenido una duración mayor a su utilidad".$^{30}$ Un camino similar utilizó Alfredo Mirande para investigar el registro histórico del tratamiento dado a los chicanos por el sistema legal y judicial. Su tesis sostenía que

desde la conclusión de la guerra entre México y Estados Unidos, los mexicanos

30 Samora y otros, Gunpowder, 1979, pp. $166-167$. 
desplazados, o chicanos, han sido objeto de un tratamiento prejuicioso y discriminatorio -un sistema de justicia de doble estándar que aplica uno a los angloamericanos y otro a los chica. nos. ${ }^{31}$

Para fundamentar esta tesis recurrió a un cúmulo de información histórica indicadora de la magnitud del problema. Concluyó con la presentación de un punto de vista teórico que apunta más hacia un choque cultural de puntos de vista del mundo que a explicaciones económicas o "patológicas" de actos de quebrantamiento de ley. Gringo justice es un reclamo explícito de una nueva interpretación de las bandas chicanas y de su ilegalidad, una interpretación fundada en la interpretación histórica de la cultura chicana.

Una de las historias políticas más innovadoras de entre las aparecidas durante la década de 1980 fue Beyond Aztlan: Ethnic autonomy in comparative perspective de Mario Barrera. ${ }^{32}$ En este trabajo el autor señala que la historia reciente de la actividad política chicana ha sido animada por dos objetivos: los intentos realizados por preservar a la comunidad y la búsqueda de la igualdad. En su evaluación de la historia del movimiento chicano, apunta que este movimiento no logró alcanzar el éxito político debido a la heterogeneidad generacional y socioeconómica de la población de habla hispana y a las contradicciones propias entre los fines de la comunidad y la igualdad. Barrera presenta un estudio comparativo de cuatro países

31 Mirande, Gringo, 1987, p. xI.

32 Barrera, Beyond, 1988. que han aplicado medidas para incluir a la pluralidad étnica: Canadá, China, Suiza y Nicaragua. Concluye señalando que lo que se necesita, a fin de prever la final asimilación de los chicanos, sería el reconocimiento oficial, por parte de Estados Unidos, del multiculturalismo. En última instancia, esto significaría el reconocimiento de un cierto grado de autonomía regional para los chicanos. De esta manera, a Barrera el análisis histórico lo llevó a una agenda política concreta de acción futura.

\section{RELACIONES CHICANAS/ESTADOS UNIDOS-MEXICO}

Uno de los cambios más sustanciales registrados durante la década de 1980 fue el incremento en la conciencia, por parte del gobierno de Estados Unidos y del público en general, de la importancia de México. Un número de sucesos y de tendencias crearon conciencia de cómo las fortunas norteamericanas están vinculadas a México. La crisis de energéticos en Estados Unidos llevó a la promoción petrolera. Cuando el precio del petróleo cayó de. bido a medidas conservacionistas y al incremento en la producción en Estados Unidos, una crisis de deuda se materializó provocando preocupación en los círculos económicos de Estados Unidos. Durante esta década recibió mucha publicidad la "guerra a las dro. gas”, que produjo grandes escándalos que alcanzaron a ciertas autoridades mexicanas y, ante la presión de Estados Unidos sobre el gobierno mexicano, se adoptaron medidas enérgicas 
contra los narcotraficantes. Las firmas multinacionales de Estados Unidos, deseosas de competir con las corporaciones japonesas, coreanas y taiwanesas, trasladaron una parte considerable de sus operaciones de ensamblado a las maquiladoras ubicadas a lo largo de la frontera con México, con lo cual se generaron miles de nuevos empleos pero, también, problemas sociales para los mexicanos norteños. Finalmen. te, una economía mexicana vacilante, producto de la crisis del endeudamien. to externo y de una prolongada guerra civil en A mérica Central apoyada por la política exterior de Estados Unidos, llevó a un mayor incremento la inmigración mexicana y centroamericana. Esto, a su vez, condujo a un largo y áspero debate sobre nuevas restricciones a la inmigración para "controlar nuestras fronteras" y, finalmente, a la Ley de Reformas y Control de la Inmigración de 1987. Tales procesos dieron a los chicanos un nuevo papel co. mo intérpretes, intermediarios y grupos de presión que el gobierno mexicano, bajo la presidencia de Salinas de Gortari, busca legitimar.

Después de todo, los chicanos, desde hace tiempo, han estado hablando sobre Aztlán como una extensión de México, y de una comunidad sin fronteras. Los chicanos hacen una crítica de casa al tratamiento que los anglos dan a los mexicanos en Estados Unidos, y aparecen como aliados en contra de los ataques racistas a la cultura mexicana. Académicamente, los chicanos tuvieron una participación creciente en conferencias y actividades con intelectuales y activistas mexicanos. En la década de 1980 los académi- cos chicanos se interesaron más en intercambios culturales con México, América Latina e incluso con Europa.

Con estos antecedentes no resulta sorprendente que los historiadores chicanos desarrollen un nuevo interés acerca de México y, al mismo tiempo, que los intelectuales mexicanos hayan empezado a conocer el trabajo de sus "primos" de Estados Unidos.

En México ha aparecido un número de antologías y traducciones sobre la historia chicana. Siglo XXI Editores, una importante casa editorial de México, publicó dos volúmenes sobre la historia laboral chicana de Juan Gómez-Quiñones y de David Maciel. ${ }^{33}$ Publicados en español, estos dos volúmenes forman parte de una pequeña aunque creciente colección de historia chicana disponible para el público mexicano. El primer volumen, de Gómez Quiñones, estudia la historia laboral chicana en la frontera mexicana hasta 1848 y apunta que, no obstante las diferencias regionales, la clase trabajadora mexicana, en ambos lados de la frontera, estaba unificada por una comunidad de cultura, creencias, rutinas de trabajo, vida familiar y organización económica. El segundo volumen, de Maciel, traza la historia de las actividades organizativas del trabajo mexicano y chicano en los movimientos laborales de Estados Unidos. Otra traducción de importancia es la del libro de David $\mathrm{J}$. Weber The mexican frontier, editado por Fondo de Cultura Económica

33 Gómez-Quiñones, Clases, 1981; Maciel, Clases, 1981. Algunas de las historias chicanas anteriores: Maciel y Bueno, Aztlan, 1976, y también editado por Maciel y Bueno, Aztlan, 1975; Gómez-Quiñones, Orígenes, 1978. 


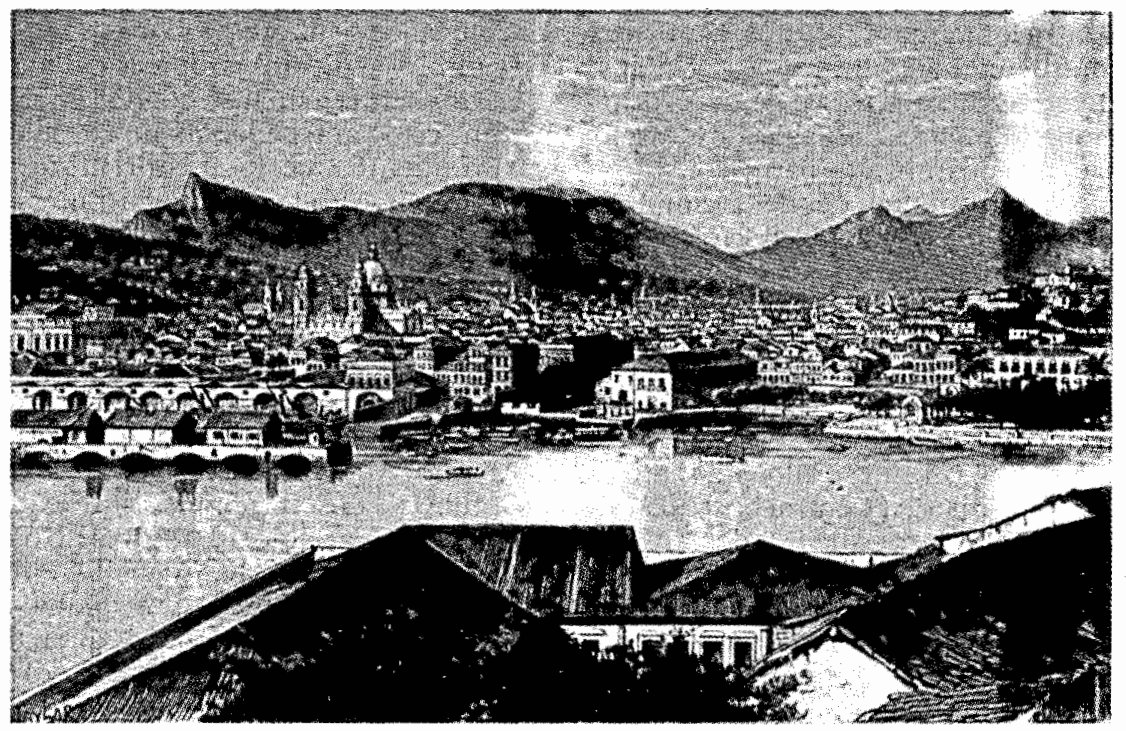

en 1988. Este trabajo permitió que un público mayor leyera la mãs reciente síntesis del periodo mexicano visto desde la perspectiva estadunidense. ${ }^{34}$

Naturalmente, también la frontera ha sido foco de atención de los historia. dores chicanos. Tres libros publicados en la década de 1980 subrayan la importancia histórica de esta región. Troublesome border, de Óscar Martinez, además de ser una historia de las complejas transformaciones étnicas, regionales e internacionales de la región, hace un llamado para un replantamiento de la frontera por parte de los políticos de Estados Unidos y México. En sus palabras:

34 Weber, Frontera, 1988.
Demográfica, económica, lingüística y culturalmente la zona fronteriza de Estados Unidos es funcionalmente una extensión de México, y de una manera similar la zona fronteriza mexicana es una extensión de la influencia económica, social y cultural de Estados Unidos [...] El reconocimiento del concepto de la "superposición" necesita hacer a un lado consideraciones de tipo nacionalista que hacen que la población vea a la frontera como una barrera intocable e impe. netrable. 35

Otro libro, The Treaty of Guadalupe Hidalgo, también se ocupó de las consecuencias sociales, legales, económicas y políticas, a largo plazo, del

35 Martínez, Troublesome, 1989, p. 145. 
establecimiento de la frontera en 1848.36 En este libro busqué examinar el impacto de este tratado en la conciencia histórica de Estados Unidos así como en la de México, además de establecer la importancia que hoy en día tiene este acuerdo. El resultado es la demostración de una comunidad de intereses históricos entre mexicanos y chicanos, centrado en las interpretaciones del significado de este docu. mento y, en última instancia, de la relación Estados Unidos-México.

Finalmente, Juan Ramón García escribió una historia sobre los esfuerzos de Estados Unidos por deportar y repatriar a un millón de mexicanos inmigrantes en 1954 mediante la Operación Espalda Mojada. ${ }^{37}$ Este estudio se basa principalmente en investigaciones realizadas en archivos de México, a partir de las cuales analiza el dilema moral que planteó para el gobierno mexicano en el momento. García encontró que los líderes chicanos no tuvieron una postura unificada en su oposición hacia esta política y que muchos productores de Texas fueron probablemente militantes del anti. $\mathrm{SNI}^{38}$. Como estudio, este libro nos presentó una opinión más complicada y menos maniquea de la Operación Espalda Mojada desde el punto de vista de ambos lados de la frontera.

Francisco Balderrama, Robert Alvares y Abraham Hoffman escribieron historias sobre las interrelaciones entre las comunidades mexicana y chica-

36 Griswold, Treaty, 1990.

37 García, Wetback, 1980. ción.

38 SN: Servicio de Naturalización e Inmigra- na en Estados Unidos. ${ }^{39}$ Balderrama investigó las actividades del consulado de México en Los Ángeles durante la década de 1930, cuando el oónsul de México trató de apoyar a los nacidos en México en su lucha por establecerse y conservar su cultura. Este libro demuestra en cierta medida la viabilidad histórica de los vínculos entre la comunidad chicana, los inmigrantes mexicanos y los representantes del gobier. no mexicano. Alvares investigó las raíces históricas de los pobladores mexicanos en Lemon Grove, California, al examinar las historias de familia de generaciones de bajacalifornianos. Demostró cómo los lazos entre familias mexicanas y de Estados Unidos se mantuvieron a través de las instituciones de parentesco, confianza y com. padrazgo. Esta historia muestra cómo las familias binacionales eran parte integral de una comunidad chicana. Hoffman estudió las consecuencias políticas y sociales del asesinato de dos jóvenes mexicanos, pertenecientes a prominentes familias mexicanas, ocurrido durante la Depresión. Hábilmente recreó las trágicas circunstancias que rodearon a los asesinatos que sucedieron en Oklahoma en 1931, a la vez que ofreció una sutil crítica del prejuicio racial judicial estadunidense.

\section{CONCLUSIONES}

Esta revisión de algunas de las principales investigaciones monográficas y libros publicados durante la década de

39 Balderrama, Defense, 1983; Alvares, Familia, 1987; Hoffman, Oklahoma, 1987. 
1980 se encuentra incompleta, ya que no he hablado de un número mayor de trabajos, del cual forman parte las antologías, los ensayos y los artículos mencionados. Sin embargo, este trabajo constituye una base representativa para la evaluación del estado actual (1990) de la historia chicana, y sugiere una posible agenda de trabajo para futuros desarrollos en esta materia.

Durante la década de 1980 el carácter del discurso en historia chicana se diversificó y se tornó más complejo. Los no chicanos comenzaron a contribuir a éste con interpretaciones del pasado mexicanoamericano. Las chicanas plantearon asuntos relacionados con los sexos, además del viejo debate sobre economía política y racismo. Los estudiosos no historiadores presentaron explicaciones del pasado utilizando sus habilidades teóricas y metodológicas. Finalmente, algunos historiadores comenzaron a ver la historia chicana desde dimensiones comparativas e internacionales.

Hubo una continuidad con el pasado al mantenerse el debate surgido entre quienes resaltaban el conflicto de la clase trabajadora y la confrontación como un importante tema interpreta. tivo frente a quienes se distinguían por subrayar la importancia de los arre. glos, los ajustes y la diversidad interna. Estas dos "escuelas", la del conflicto y la de los puntos de vista pluralistas de la historia chicana, continuaron sus debates con trabajos históricos representativos de ambas, escritos por Rudolfo Acuña (conflicto) y Mario García (pluralista), aparecidos durante la década. La mayoría de las historias políticas tuvieron como método de análisis el del conflicto, mientras que la mayor parte de los estudios que versaron sobre la comunidad, lo social y lo intelectual tendieron hacia un enfoque pluralista.

Toda una gama de "otras" interpretaciones surgieron para desvanecer estas lineas de batalla. Algunos historiadores, como De León, Ruiz, Martínez y Deutsch, evaluaron el conflicto y el acuerdo como importantes temas en la historia. Otros, entre los que se cuentan Mazon y Monroy, vieron al conf licto como una manifestación superficial de fuerzas psicológicas y culturales más profundas. En efecto, la tendencia hacia la conceptualización de la historia chicana con la utilización de términos como sexo y clase y una diferenciación generacional, parecen hacer interna la idea de conflicto. Es factible que en el futuro los historiadores chicanos se encuentren ante una mayor diferenciación y una mayor disensión interna que en el pasado.

Si bien tuvo lugar una explosión creativa en el estudio histórico de los chicanos durante esta década, no existe la seguridad de que ésta continúe durante la década de 1990 . Uno de los hechos más preocupantes de la década de 1980 y de la presente es el relativamente pequeño número de chicanos que están ingresando a los programas de doctorado en historia, en comparación con los números registrados durante las décadas de 1960 y 1970. No podemos esperar el surgimiento de un gran número de nuevos talentos en la década de 1990. Habrá nuevos y prometedores trabajos de la. tinas y chicanas, muchas de las cuales apenas inician sus carreras, y pode- 
mos esperar críticas sobre los sexos basadas en una historia chicana centrada en los hombres mayores. Sin embargo, a menos que los historiadores chicanos de la vieja generación continúen siendo tan creativos como lo fueron en sus años de juventud ( $¿$ existe un punto de utilidades decrecientes?), hemos de esperar a la maduración de ciertos puntos de vista, quizá un inevitable viraje hacia actitudes más conservadoras. En otra parte de este trabajo, al evaluar la historia chicana de California, apunté que esto ya ha sucedido. Sin embargo, ese pesimista punto de vista puede no ser garantizable, dado un enfoque más amplio.

¿Cuál sería la agenda de trabajo para el futuro progreso de nuestra materia de estudio? En primer lugar, se necesita infundir un mayor entusiasmo a los latinos y chicanos para que se especialicen en historia y obtengan grados académicos. Para lograrlo, debemos tener un mayor número de profesores que ocupen cátedras de historia en los Departamentos de Historia y que funjan como mentores y modelos. Para promover este proceso y actuar como agencia de información sobre becas, oportunidades de trabajo y similares, requerimos de una organización específica disciplinada. Desde hace tiempo la Asociación Nacional de Estudios Chicanos ha reconocido y ha hablado en contra de problemas sistemáticos inherentes a todas las disciplinas, pero se requiere hacer esfuerzos especiales para unir a los historiadores chicanos en un colegio en el seno de la ANECH O en una organización separada. Esta organización daría una mayor visibilidad e importancia a la historia chicana co- mo un campo de estudio en el marco de los estudios chicanos.

Otro tema de trabajo futuro sería el tendiente a restablecer una publicación periódica académica que brinde oportunidades de publicación a los historiadores chicanos. Hace varios años, The Journal of Mexican American History tuvo una quijotesca y breve vida como publicación periódica; por supuesto que ha habido otras revistas chicanas que, a través de los años, han publicado temas de historia. Sin embargo todas han desaparecido. La única sobreviviente como revista multidisciplinaria de estudios chicanos nacionalmente reconocida es Aztlan, publicada en la Universidad de California en Los Ángeles. Una revista especializada en historia latina y chicana estimularía y animaría a los nuevos talentos. Las dificultades económicas y de tipo organizativo de una tarea de esta naturaleza resultan obvias. Una publicación de este tipo, con toda seguridad tendría que ser subsidiada por una universidad con un nivel de primera en cuanto a investigación, y requeriría de la dedicación de un historiador chicano con muchos años de experiencia, que la condujera exitosamente.

Por último, es de indicar que los cambios demográficos registrados durante la pasada década van a requerir que los historiadores chicanos amplíen su conceptualización de la comunidad chicana y de la historia chicana. Me refiero a los millones de habla hispana que no son mexicanos, residentes en Estados Unidos, que eufemística y controvertidamente han sido amontonados bajo el calificativo de “hispánicos". La tendencia acusada en 
los últimos años por los chicanos de adoptar la denominación de "latino" es solamente un síntoma del profundo cambio experimentado en la orientación hacia un mayor enfoque panlatino en los estudiosos chicanos. Estoy convencido de la futura aparición de un número de trabajos de investigación histórica comparativa realizados por chicanos y por otros latinos conforme se den los pasos para la conceptualización de una más amplia historia del latino. La población de origen puertorriqueño, cubano, dominicano, salvadoreño, guatemalteco y panameño está incrementándose en Estados Unidos y demandará un presencia histórica. Durante la década de 1990 habrá de responderse a cómo sus comunidades serán interpretadas a la luz de la historiografia chicana.

\section{BIBLIOGR AFÍA}

-Acuña, Rudolfo, Community under siege a chronicle of chicanos east of the Los Angeles river 1945-1975, Chicano Studies Research Center, Los Ángeles, 1984. , Occupied America: A history of chicanos, Prentice Hall, Nueva York, 1987.

, "The struggles of class and gender: Current research in Chicago studies", Journal of Ethnic Studies, primavera 1990, pp. 135-138.

-Alanís Enciso, Saúl Fernando, "La primera gran repatriación: los mexicanos en Estados Unidos y el gobierno de México (19181922)", tesis de licenciatura en historia, Facultad de Filosofia y Letras, UNAM, 1987.

-Allsup, Carl, The American G. I. Forum: Origins and evolution, Center for Mexican American Studies, University of Texas Press, Austin, 1982.
-Alvares, Jr., Robert R., Familia: Migration and adaptation in Baja and Alta California. 1800-1975, University of California Press Berkeley, Los Ángeles, Londres, 1987.

-Balderrama, Francisco, In defense of la Raza: The Los Angeles mexican consulate and the mexican community, 1929 . 1936, University of Arizona Press, Tucson, 1983.

-Bannon, John Francis, The spanish borderlands frontier, 1513-1821, Nueva York, 1970.

-Barrera, Mario, Beyond Aztlan: Ethnic autonomy in comparative perspective, Praeger, Nueva York, Westport, Connecticut y Londres, 1988.

-Blackwelder, Julia Kirk, Women of the Depression: Caste and culture in San Antonio 1929-1939, Texas A \& M Press, College Station, 1984.

-Camarillo, Albert, Chicanos in a changing society: From mexican pueblos to american barrios in Santa Barbara and Southern California 1848-1930, Harvard University Press, Cambridge, 1979.

- Carreras de Velasco, Mercedes, Los mexicanos que devolvió la crisis, 1929. 1932, Secretaría de Relaciones Exteriores, México, 1974.

-Castillo, Adelaida del (comp.), Between borders: Essays on mexicana/chicana history, Floricanto Press, Encino, 1990.

-Castillo, Pedro y Alberto Camarillo (comps.), Furia y muerte: los bandidos chicanos, Aztlan Publications, Los Ángeles, 1973.

-Chávez, John R., "Rubio's Stolen heritage in tejano historiography", manuscrito inédito presentado en la Asociación Nacional de Estudios Chicanos, 4 marzo 1989.

-Cue Cánovas, Agustín, Los Estados Unidosy el México olvidado, Costa-Amic, México, 1970.

-Deutsch, Sarah, No separate refuge: Culture, class and gender on the anglo- 
hispanic frontier in the american south west 1880-1940, Oxford University Press, Nueva York, 1987.

-Fannon, Franz, The wretched of the earth, Grove Press, Nueva York, 1963.

-García, Ignacio M., United we win: The rise and fall of La Raza Unida Party, University of Arizona Press, Tucson, 1989.

- García, Juan Ramón, Operation Wetback: The mass deportation of mexican undocumented workers in 1954, Green. wood Press, Westport, Connecticut, 1980.

-García, Mario T., Desert immigrants. The mexicans of El Paso. 1880-1920, Yale University Press, Londres y New Haven, 1980.

-Garcia, Richard, The rise of the mexican american middle class: San Antonio, 1829-1941, Texas A \& M Press; College Station, 1991.

-Gómez Arnau, Remedios, México y la protección de sus nacionales en los Estados Unidos, Centro de Investigación Sobre los Estados Unidos de America, México, 1990.

-Gómez-Quiñones, Juan, Sembradores: Ricardo Flores Magón y el Partido Liberal Mexicano: A eulogy and critique, Chicano Studies Research Center, Los Ángeles, 1983.

, Orígenes del movimiento obrero chicano, Ediciones Era, México, 1978.

La clase obrera en la historia de México: al norte del río Bravo (pasado lejano) (1600-1930), Siglo XXI Editores, México, 1981. , Chicano politics: reality $\varepsilon$ promise. 1940-1990, University of New Mexico Press, Albuquerque, 1990. , y Luis Arroyo, "On the state of chicano history: Observations on its development, interpretation and theory, 1970-1974", Western Historical Quarterly, vol. xI, núm. 3, julio 1980, pp. 307 322.

-González, Gilbert, Chicano education in the era of segregation, The Balch
Institute Press, Filadelfia, 1990.

-Griswold del Castillo, Richard, The Los Angeles barrio 1850-1890: a social history, University of California Press, Berkeley y Los Ángeles, 1980.

, "New perspectives on the mexican and american borderlands", $\mathbf{L a}$ tin American Research Review, vol. 19, núm. 1, 1984, pp. 199-209. , La familia: chicano fami. lies in the urban Southwest, 1848 to the present, University of Notre Dame Press, Notre Dame, 1984. , "Tejanos and California chicanos: Regional variations in mexican american history", Mexican Studies/Estudios Mexicanas, vol. 1, núm. 1, inviemo 1985, pp. 134139. , "Southern California chicano history: Regional origins and a national critique", Aztlan: A Journal of Chicano Studies, vol. XIX, núm. 1, 1988-1990, pp. 109-124.

, The Treaty of Guadalupe Hidalgo: a legacy of conflict, University of Oklahoma Press, Norman, 1990.

-Gutiérrez, David, "The third generation: Reflections on recent chicano historiography", Mexican Studies, vol. 5, núm. 2, verano 1989, pp. 281-297.

-Gutiérrez, Ramón, When Jesus came the corn mothers went away: Marriage, sexuality and power in New Mexico, 1500-1846, Stanford University Press, Palo Alto, 1990.

-Hinojosa, Gilberto Miguel, A border lands town in transition: Laredo, 1755 . 1870, Texas A \& M Press, College Station, 1983.

-Hoffman, Abraham, Unwanted mexi. can americans in the Great Depression. Repatriation pressures. 1929-1939, University of Arizona Press, Tucson, 1974. "The writing of chicano urban history: From bare beginnings to significant studies", Journal of Urban History, vol. XII, núm. 2, febrero 1986, pp. 199-205. , An Oklahoma tragedy: The shot ting of the mexican studies, 1931 , Te- 
xas Western Press/University of Texas, El Paso, 1987.

-León, Arnoldo De, "Texas-mexicans: Marginal folks or historical insiders", manuscrito inédito.

A social history of Duval county, County Commissioners' Court, San Diego, Texas, 1978.

Las fiestas patrias: biographic notes on the chicano presence in San Angelo. Texas, Caravel Press, San Antonio, 1978.

, Benavides: The town and its founder, Benavides Centennial Committee, Benavides, Texas, 1980.

The tejano community. 1836-1900, University of New Mexico Press, Albuquerque, 1982.

, Ethnicity in the sunbelt: $M e$ xican americans in Houston, Texas, Mexican A merican Studies Center, Houston, 1989.

Tejanos and the numbers game, University of Notre Dame Press, Albuquerque, 1989.

, "Texas mexicans: Twentieth

century interpretations", en Walter Buenger y Robert A. Calvert (comps.), Texas through time: Evolvina interpretations, Texas A \& M University Press, College Station, 1990.

-López y Rivas, Gilberto, Chicano o la explotación de "La Raza", Editorial Imprenta Casas, México, 1969.

Los chicanos: una minoría nacional explotada, Nuestro Tiempo, México, 1971.

, La guerra de 47 y la resistencia popular a la ocupación, Editorial Nuestro Tiempo, México, 1976.

-Maciel, David, La clase obrera en la historia de México: al norte del río Bravo (pasado inmediato) (1930-1981), Siglo XXI Editores, México, 1981.

_...... y Patricia Bueno (comps.), Aztlán: historia del pueblo chicano, 1848-1910, Secretaría de Educación Pública, México, 1975.
Aztlán: historia contemporánea del pueblo chicano, Secretaria de Educación Pública, México, 1976.

-Martínez, Óscar, Troublesome border, University of Arizona Press, Tucson, 1989.

-Mazon, Mauricio, The zoot suit riots: The psychology of symbolic annihilation, University of Texas Press, Austin, 1984.

-Mirande, Alfredo, Gringo justice, University of Notre Dame Press, Notre Dame, 1987.

-Monroy, Douglas, Thrown among strangers: The making of mexican culture in frontier California, University of $\mathrm{Ca}$ lifornia Press, Berkeley y Los Ángeles, 1990.

-Montejano, David, Anglos and mexicans in the making of Texas. 1836-1986, University of Texas Press, Austin, 1987.

-Muñoz Jr., Carlos, Youth identity power: The chicano movement, Verso Press, Londres y Nueva York, 1989.

-Nash, Jeffery y otros, The american people: Creating a nation and a society, Harper \& Row, Nueva York, 1986.

-Ortiz, Isidro, "Reagonomics and latino organizational strategies", en Sucheng Chan (comp.), Ethnic and gender boundaries in the United States: Studies of asian black mexican and native americans, Edwin Mellen Press, Nueva York, 1989.

-Peña, Manuel, The Texas mexican conjunto: $A$ history of working class music, University of Texas Press, Austin, 1985.

-Ríos Bustamante, Antonio y Pedro Castillo, An illustrated history of mexican Los Angeles 1781-1985, Chicano Studies Research Center, Los Ángeles, 1986.

-Romo, Ricardo, East Los Angeles: History of a barrio, University of Texas, Austin, 1983.

-Rosenbaum, Robert J., Mexicano resistance in the Southwest: "The sacred right of self preservation", University of Texas Press, Austin, 1981.

-Rubio, Abel, Stolen heritage: $A$ mexi- 
can american's rediscovery of his family's lost land grant, Eakin Press, Austin, 1986.

-Ruiz, Vickie, "Texture, text, and context: New approaches in chicano historiography", Mexican Studies/Estudios Mexicanos, vol. 2 , núm. 1 , invierno $1986, \mathrm{pp}$. 145-152.

, Cannery women: Cannery lives -mexican women unionization, and the California food processing industry 1930-1950, University of New Mexico Press, Albuquerque, 1987.

, y Susan Tiano (comps.), Women on the U.S. Mexico border: Responses to change, Westview Press, Boulder, Colorado, 1987.

-Said, Edward, Orientalism, Panthcon Books, Nueva York, 1978.

-Samora, Julián, Joe Bernal y Albert Peña, Gunpowderjustice: A reassessment of the Texas rangers, University of Notre Dame Press, Notre Dame, 1979.

-San Miguel Jr., Guadalupe, "Let all of them take heed": Mexicanamericans and the campaign for educational equality in Texas 1910-1981, University of Texas Press, Austin, 1987.
-Santamaría Gómez, Arturo, La izquierda norteamericana y los trabajadores indocumentados, Ediciones de Cultura Popular/UnAM, México, 1988.

-Saragoza, Alex, "Ideological distortions in recent chicano historiography: The internal model and chicano historiographical interpretation", Aztlan: A Journal of Chicano Studies, vol. XVIII, núm. 1, primavera 1987 , pp. 7-28.

"Recent chicano historiography: An interpretive essay", Aztlan: $A$ Journal of Chicano Studies, vol. XIX, núm. 1, 1988-1990, pp. 1-78.

-Sheridan, Thomas E., Los tucsonenses: The mexican community in Tucson 1854-1941, University of Arizona Press, Tucson, 1986.

-Weber, David, The mexican frontier: 1821-1846. The american Southwest under México, University of New Mexico Press, Albuquerque, 1982.

-Zavella, Patricia, Women's work and chicano families: Cannery workers of Santa Clara Valley, Cornell University Press, Nueva York, 1987. 


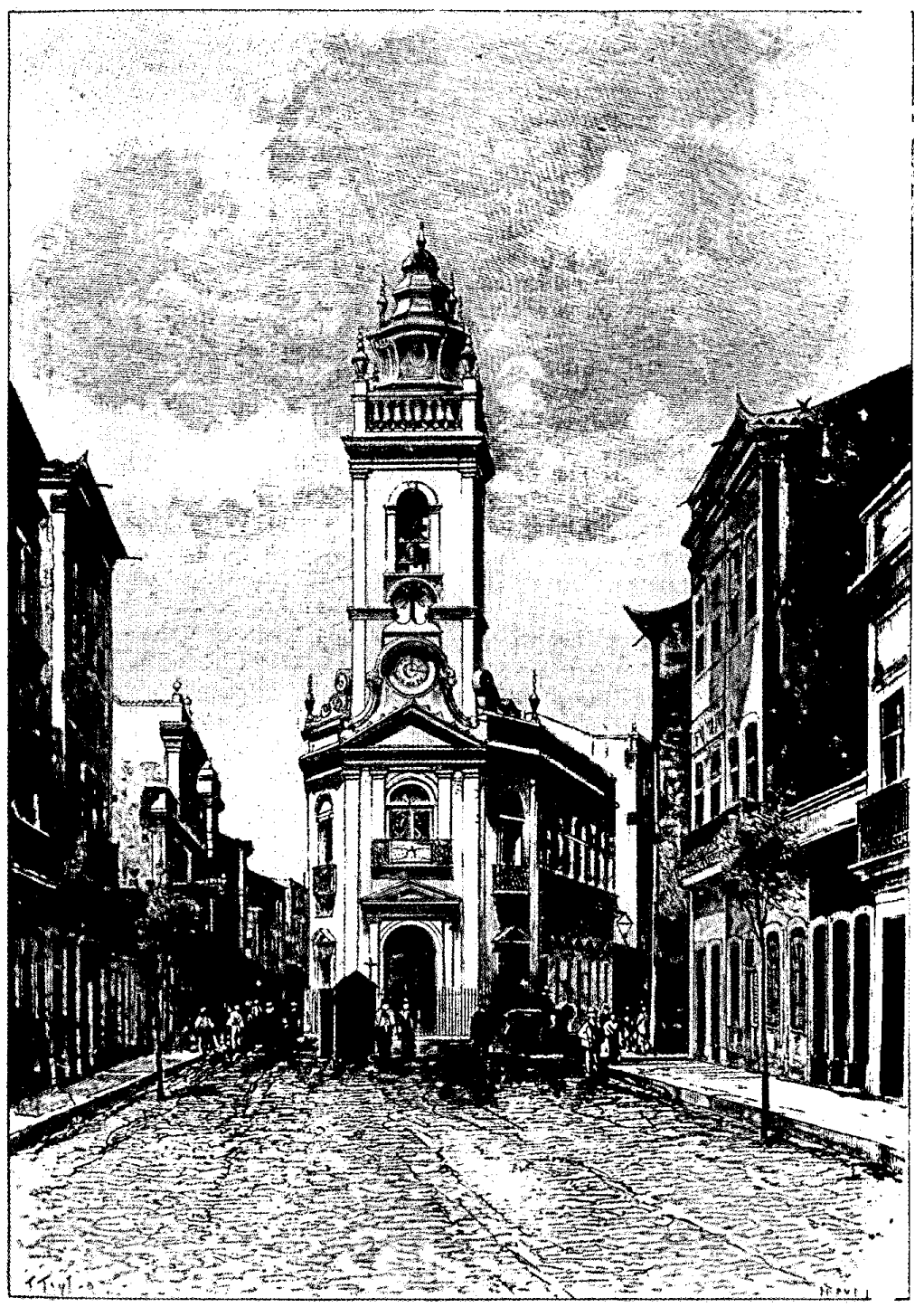

